\title{
lodometric determination of glucose and ribose using potassium iodate as novel reagent in acetic acid medium
}

\begin{abstract}
In this work, we have reported a simple, cost effective and reliable method for the determination of glucose iodometrically by making use of potassium iodate. This volumetric method determines glucose instantly, thereby greatly reduces the time of determination.
\end{abstract}

Keywords: $\mathrm{HIO}_{3}$, glucose, iodometry, molecular weight, gluconic acid, distilled water, oxidation, hydroxyl group, sodium thiosulphate, metabolism, colorimetric, aromatic amines
Volume 8 Issue 5 - 2019

\author{
Prakruthi Aiyappa K, Harshitha BL, Chaitra \\ Shivani KS, Lokanatha Rai KM \\ Department of chemistry, University of Mangalore, India
}

Correspondence: Lokanatha Rai KM, department of chemistry, Mangalore University, PG centre, Jnanakaveri, Chikaluvar, Kodagu, India, Email kmlrai@yahoo.com

Received: September 16, 2019 | Published: October 04, 2019

\section{Introduction}

Glucose is the major carbohydrate found in blood and a chief source of energy in human body. The blood glucose levels are perfectly maintained under the influence of hormones like insulin. However the hormonal imbalance sometimes may result in abnormalities of glucose metabolism and results in diseased condition. ${ }^{1}$ Thus the detection of blood glucose levels can provide a basic understanding of the malfunctioning of the tissues and body. Although various methods are reported in the literature for the determination of glucose, few are commonly used via, colorimetric method, Benedict's method, ${ }^{2}$ Bertrand's method, ${ }^{3}$ Hagedorn-Jenson method, ${ }^{4}$ chloramine- ${ }^{5}$ method etc.

Literature survey revealed that combination of iodic acid and potassium iodide has been used for tri-methylsilylation of alcohols and phenols in the presence of HMDS and iodination of aromatic amines. ${ }^{6}$ Recently Kelsey B LaMartina et al., ${ }^{7}$ showed that the combinations of ammonium iodate and catalytic $N$-hydroxyphthalimide (NHPI) in presence of acetic acid for the selective oxidation of $n$-butyl benzene directly to 1-phenylbutyl acetate in high yield ${ }^{7}$ and it is also reported as catalyst for the $\alpha$-sulfenylation of enaminones. ${ }^{8}$ Recently Rai et al., ${ }^{9}$ used $\mathrm{KIO}_{3}$, as a novel oxidizing agent for the synthesis of isoxazolines. ${ }^{9}$

In continuation of our work on synthetic and analytical applications of $\mathrm{HIO}_{3}$, we thought of an operationally simple titrimetric method for the determination of glucose. The method reported here makes use of the fact that glucose is known to undergo oxidation by $\mathrm{HIO}_{3}$, yielding gluconic acid involving one molecule of $\mathrm{HIO}_{3}$ per molecule of glucose. From the mechanism shown below, it is evident that the reactive site involved for the attack of $\mathrm{HIO}_{3}$ is the anomeric hydroxyl group. This moiety is more reactive than the other functional groups. Therefore in the presence of other materials $\mathrm{HIO}_{3}$ first reacts with glucose and the rest needs more time to react under the experimental condition.

\section{Materials and method}

All reagents and chemicals used were of analytical reagent grade and were procured from SRL, India. Distilled water was used throughout the experiment. In a typical experiment, a known excess of standard solution of $\mathrm{HIO}_{3}$ was added to a known amount of glucose. After completion of the reaction, unreacted $\mathrm{HIO}_{3}$ was determined by iodometry. By carrying out a blank experiment simultaneously, the amount of $\mathrm{HIO}_{3}$ consumed was determined. As the overall reaction requires one mole of $\mathrm{HIO}_{3}$ per molecule of glucose, which is equivalent to one mole of iodine and hence the molecular weight ' $\mathrm{m}$ ' of glucose is determined using the following equation.

1 Mole of sugar $\equiv 1 \mathrm{~mol}$ of $\mathrm{I}_{2} \equiv 2000 \mathrm{ml}$ of $1 \mathrm{~N}$ Sodium thisulphate solution

$$
M=\frac{2000 \times w}{\left(V_{1}-V_{2}\right) \times N}
$$

Where, $\mathrm{m}=$ Molecular weight of Glucose

$\mathrm{W}=$ Weight of the given sample

$\mathrm{V}_{2}=$ Volume of sodium thiosulphate consumed (Blank)

$\mathrm{V}_{1}=$ Volume of sodium thiosulphate consumed (experimental)

$\mathrm{M}=$ molarity of sodium thiosulphate

Determination of molecular weight of glucose/ribose: An accurately weighed (20-60mg) sample of glucose/ribose was dissolved in distilled water $(10 \mathrm{ml})$ in an Erlenmeyer flask. To this, a solution of $0.01 \mathrm{~mol}$ of $\mathrm{HIO}_{3}$ was introduced and it was heated to about $65^{\circ} \mathrm{C}$ on water bath, to this solution about $5 \mathrm{ml}$ of dilute sulphuric acid and $5 \mathrm{ml}$ of $10 \%$ potassium iodide was added and the liberated iodine was titrated against the standardized sodium thiosulphate solution using starch as indicator. In a similar way, a blank titration was conducted without adding glucose. From the difference in the volume of sodium thiosulphate solution consumed, the molecular weight ' $\mathrm{m}$ ' was calculated using the above equation.

\section{Results and discussions}

The method reported here makes use of the fact that glucose is known to undergo an oxidative dehydrogenation by $\mathrm{HIO}_{3}$, yielding the gluconic acid by consuming one mole of $\mathrm{HIO}_{3}$ per one molecule of 
glucose or ribose (Scheme 1). Generally a known volume of $\mathrm{HIO}_{3}$ is added to known mass of Glucose, after the completion of the reaction, the unreacted $\mathrm{HIO}_{3}$ is determined iodometrically. By carrying out a parallel blank experiment the amount of the $\mathrm{HIO}_{3}$ consumed is determined. As the overall reactions require one mole CAT per one mole of the Glucose, which is equivalent to mole of iodine, weight of the Glucose is determined by using equation shown above.

$\mathrm{KIO}_{3}+\mathrm{AcOH} \longrightarrow \mathrm{HIO}_{3}+\mathrm{AcOK}$

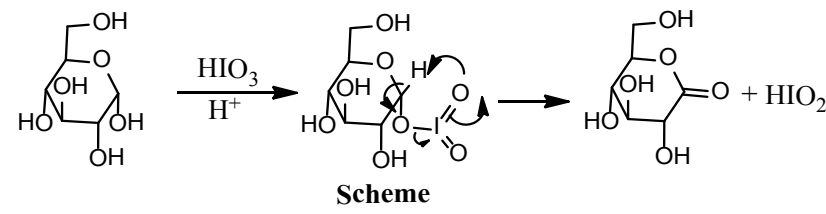

\section{Scheme I}

\section{Conclusion}

We have developed a reliable, cost effective method for the determination of glucose using mild conditions and without the use of any sophisticated instruments and also this method requires short time.

\section{Acknowledgements}

All the authors are grateful to the Department of chemistry, Mangalore University, PG centre, Chikaluvar, Kodagu, Karnataka, India for providing lab facilities for carrying out this work.

\section{Conflicts of interest}

The author declares that there are no conflicts of interest.

\section{References}

1. Trinder $P$, Determination of blood glucose using an oxidaseperoxidase system with a non-carcinogenic chromogen. $J$ Clin Pathol. $1969 ; 22(2): 24-27$

2. Benedict SR. The determination of blood sugar. J Biol Chem. 1925;207213

3. A Shaffer, AF Hartmann. The Iodometric determination of copper and its use in sugar Analysis: Other solutions sugars in Blood, Urine, Milk, and determination of reducing analysis. J Biol Chem.1921;45:365-390.

4. Von FW Kuntze, H RODECK. Untersuchungen an Kindern fiber TagbTacht-Unterschiede bei kombinierter Glucose-Wasser-Belastung. Bioehem Zeitschr. 1923;135:46.

5. Vatsala U, Sumana Y, Kotian Narayana U, et al. Iodometric Determination of Glucose using Chloramine-T. J Chem Biol and Phy Sci. 2017;7:868-870.

6. Mohammad Ali Zolfigol, Ardeshir Khazaei, Eskandar Kolvari, et al. $\mathrm{HIO}_{3} / \mathrm{KI}$ : A new combination reagent for iodination of aromatic amines and trimethylsilylation of alcohols and phenols through in situ generation of iodine under mild conditions. ARKIVOC. 2009;200-210.

7. Kelsey B LaMartina, Haley K Kuck, Linda S Oglesbee, et al. Selective benzylic C-H monooxygenation mediated by iodine oxides. Beilstein J Org Chem. 2019;15:602-609.

8. Houjuan Qia, Min Tenga, Miao Liuc, et al. Regular ArticleBiomassderived nitrogen-doped carbon quantum dots: highly selectivefluorescent probe for detecting Fe3+ions and tetracyclines. Journal of colloid and interface science. 2019;332-341.

9. Sumana Y Kotian, Abishad PMK Byrappa, KM Lokanatha Rai Potassium iodate $\left(\mathrm{KIO}_{3}\right)$ as a novel reagent for the synthesis of isoxazolines: evaluation of antimicrobial activity of the products. J Chem Sci. 2019;131:46. 